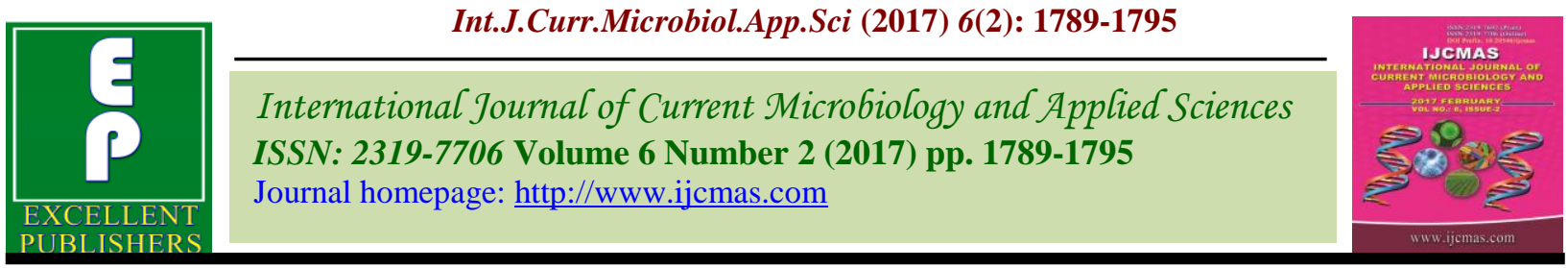

Original Research Article

http://dx.doi.org/10.20546/ijcmas.2017.602.200

\title{
Isolation and Identification of Fungi from Soil in Loyola College Campus, Chennai, India
}

\author{
M. Raja*, G. Praveena and S. John William \\ P.G and Research Department of Advanced Zoology and Biotechnology, Loyola College, \\ Chennai 600 034, India \\ *Corresponding author
}

\begin{tabular}{|c|c|}
\hline & A B S T R A C T \\
\hline $\begin{array}{l}\text { Ke y w o r d s } \\
\text { Isolation, } \\
\text { Soil fungi, } \\
\text { microbial } \\
\text { pathogens. }\end{array}$ & \multirow{3}{*}{$\begin{array}{l}\text { The investigation was conducted to find out the fungal diversity in soil samples } \\
\text { collected from Loyola college campus, Chennai. In my investigation } 25 \text { isolates } \\
\text { obtained from the soil samples. Among the } 28 \text { isolates } 13 \text { were identified with } \\
\text { standard key and microbial expert. From the fungal isolates the most of the species } \\
\text { belonging to the genera Aspergillus and Mucor were dominant. The identified soil } \\
\text { fungi namely Aspergillus niger, Aspergillus clavatus, Aspergillus sydowii, } \\
\text { Aspergillus variabilis, Aspergillus fumigatus, Penicillium chrysogenum, } \\
\text { Colletotrichum gloeosporioides senu lato, Mucor sp. Rhizopus stolonifer, Rhizopus } \\
\text { oryzae, Cunninghamella bertholletiae, Scopulariopsis brumptii, Cladophialophora } \\
\text { sp. Among the identified species the Keratinophilic fungi Aspergillus niger found } \\
\text { maximum numbers in the campus and followed by Mucor sp. }\end{array}$} \\
\hline Article Info & \\
\hline $\begin{array}{l}\text { Accepted: } \\
\text { 24 January } 2017 \\
\text { Available Online: } \\
\text { 10 February } 2017\end{array}$ & \\
\hline
\end{tabular}

\section{Introduction}

The soil serves as a reservoir for many microbial communities of plants and herbs which can be producing, $\mathrm{CO}_{2}$ and nitrogen cycle. The microorganisms plays major role in soil ecosystem. Microbial composition and functioning changes the soil quality through decomposition of organic matter, recycling of nutrients and biological control (Stefanis et al., 2013). Soil is an oligotrophic medium for the growth of fungi because the fungal growths are extremely limited for most of the time and readily available are present for short periods in a limited zone. For most of the time, fungi are either dormant, or they metabolize and grow very slowly utilizing a range of organic molecules. The fungi distribute organic matter away from the roots. In general, the concentration of microbes is greatest close to the surface of roots (rhizosphere) and hyphae of arbuscular mycorrhizal fungi (mycorhizosphere), where exudates are extraordinarily important source of organic energy entering from soils. Genetic studies have shown that fungi are more closely related to animals than to plants. Fungi have 80 percent or more of the same genes as humans (Ratnakumar et al., 2015; Dick, 2009 and Kirk, 2004).

Fungi are not only beautiful but play a significant role in the daily life of human beings besides their utilization in industry, 
agriculture, medicine, food industry, textiles, bioremediation, natural cycling, as bio fertilizers and many other ways. Fungal biotechnology has become an integral part of the human welfare (Karthikeyan et al., 2014).

Fungus benefits most plants by suppressing plant root diseases and fungi promote healthier plants buy attacking plants pathogens with fungal enzymes. Fungi also use antagonism to reduce competition by producing antibodies, which suppress other microorganisms from growing. They produce many vitamins which promote plant growth. Beneficial fungi also form protective webs and nets around roots and leaves to protect the host plants (Lowenfels and Lewis, 2006; Sylvia et al., 2005). Fungus also protects plants by supplying a protective health to supply both water and phosphorus to the plant roots during droughts (Magdoff and VanEs, 2009). The present studies were identified fungal community from soil samples collected from different locations of Loyola college campus and it was identified with microbial expert.

\section{Materials and Methods}

\section{Collection sites}

The Loyola college campus was divided into 20 zones and each zone five location were selected and each location soil samples were collected near roots where, most of the microbial activity is concentrated. Soil samples (approximately 5g) were collected with clean dry and sterile polythene bags along with sterile spatula. The collected samples brought to the laboratory and preserved for further studies. The soil samples were collected from the month of September 2015 to March 2016 in Loyola college campus at various locations. The soil samples collected from twenty different zones of Loyola college campus mentioned in Table 1.

\section{Preparation of soil sample and microbial culture}

In systematic screening process for isolation of fungus 20 soil samples collected at different location inside the Loyola campus. Samples were collected near roots where most of the microbial activity is concentrated. From the collected soil samples (Soil dilution method: Waksman, 1927) diluted with 1g soil is in $10 \mathrm{ml}$ of sterile distilled water. $1 \mathrm{ml}$ of suspension was added to sterile petriplates in triplicates containing sterile Potato Dextrose Agar the plates were incubated at $28^{\circ} \mathrm{C}$ for 5 7 days. A greater number of species was isolated most of the fungus sporulate heavily. Pure culture was done using test tube containing fresh agar slants of PDA medium. The test tubes are stored in refrigerator. When inoculums were transferred into petriplates containing nutrient media cells are not separated from each other. Therefore, there develop mixed colonies. Hence isolation of pure culture from mixed colonies is rather difficult. Therefore spread plate technique is employed for pure culture (Labeda, 1992; Seifert, 1992 and Bacon, 1992).

\section{Staining of fungi}

The fungal propagules either are hyaline (colourless) or different colours. The hyaline mycelia /spores/conidia and cytoplasm can be stained by using Lactophenol and cotton blue was used. Cotton blue were stained cytoplasm and results in light blue background. Lacto phenol acts as a cleaning agent. The stained specimens was observed under the light microscope (Magnus MLXi plus) for identification and microphotograph was taken under 10X $\times 40 \mathrm{X}$ magnification.

\section{The effect of Lactophenol Cotton Blue}

LPCB is a stain used for making semipermanent microscopic preparation of fungi 
The LPCB stain has three following components. Phenol: kills any organism. Lactic acid: preserves fungal structures Cotton blue: stains the chitin and cellulose of the fungal cell wall intensely blue.

\section{Identification of Fungi}

The isolated fungi were identified to the genus level and to the species when possible on the basis of macro morphological (The colonies were examined for slow or for rapid growth, topography (flat, heaped, regularly or irregularly folded), texture (yeast like, powdery, granular, velvety or cottony), surface pigmentation and reverse pigmentation) and micro morphological (Hyphae, macro conidia, micro conidia, chlamydospores and other special fungal structure) characteristics using suitable media, slide cultures and the most updated keys for identifications. The identified fungi confirmed with microbial expert.

\section{Results and Discussion}

The study aimed that the isolation of soil fungi from different locations of Loyola college campus grown in vitro during the period of November 2015 to March 2016. Isolated fungi was identified by some key with help of standard books and the confirmation was done by Dr. Swaranjit Singh Cameotra, Professor, Deputy Director, Isititute of Microbial Technology, Chandigarh.

In my investigation 28 isolates obtained from the soil samples. Among the 25 isolate 13 were identified with standard key and microbial expert. From the fungal isolates the most of the species belonging to the genera Aspergillus and Mucor were dominant.

The identified soil fungi (Table 2 \& 3) namely Aspergillus niger, Aspergillus clavatus, Aspergillus sydowii, Aspergillus variabilis, Aspergillus fumigatus, Penicillium chrysogenum, Colletotrichum gloeosporioides senu lato, Mucor sp. Rhizopus stolonifer, Rhizopus oryzae, Cunninghamella bertholletiae, Scopulariopsis brumptii, Cladophialophora sp. Among the identified species the Keratinophilic fungi Aspergillus niger found maximum numbers in the campus and followed by Mucor sp.

Soil is a multi-layered surface complex of mineral and organic constituents present in solid liquid and gaseous states. The mineral portion of soil results from the actions of weathering and erosion on rock (Dannis, 2012). Broad soil type-and, slit or clay-is defined as largest to smallest of particle size. These particles pack loosely, and pore spaces, and plant roots are particular habitats for microorganisms, often in bio films. Soil also contains plants, animal carcasses and manmade materials.

A gram of garden soil can contain around one million fungi such as yeasts, and moulds. Fungi have no chlorophyll and are not able to photosynthesise. They cannot use atmospheric carbon dioxide as a source of carbon; therefore they are chemo heterotrophic meaning that, like animals they require a chemical source of energy rather than being able to use light as an energy source as well as organic substrates to get carbon for growth and development. Many fungi are parasitic, often causing disease to their living host plant although some have beneficial relationship with plants. In terms of soil and humus creation, the most important fungi tend to be saprotrophic they live on dead or decaying organic matter, thus breaking it down and converting it to forms that are available to the higher plants.

Wherever adequate moisture, temperature and organic substrates are available fungi are 
present. Although we normally think of fungi as growing in warm moist forest, many species occur in habitats that are cold, periodically arid, or otherwise seemingly inhospitable. It is important to recognise that conditions for growth and reproduction vary widely with fungal species. Diversity of most groups of fungi tends to increase in tropical regions, but detailed studies are only in their infancy (Isaac et al., 1993). From the mycelia the fungi is able to throw its fruiting, the visible part above the soils (e.g. mushrooms, toadstools, puffballs), which may contain millions of spores. When the fruiting body bursts, these spores are dispersed through the air to settle in fresh environments and are able to lie dormant for up to years until the right conditions for their activations arise or the right food is made available.

I have chosen this study, because it is an effort to understand the soil fungal diversity in Loyola College Campus. The environmental factors such as $\mathrm{pH}$, temperature, moisture, organic carbon and nitrogen play an important role in distribution of mycophora. The soil moisture has a direct effect on the population of fungi positively hence, at higher moisture the tolerance and colonization is badly affected (Adams et al., 1999).

Several reviews exist of recent, successful techniques for isolating fungi from nature (Labeda, 1992). Seifert (1992) includes basic techniques for isolating specific taxonomic groups and from specific habitats and Bacon (1992), in discussing the endophytic fungi of grasses, includes techniques that could be applied to other substrates. As above, Bills and Polishook (1994) have demonstrated the value of particle filtration for the isolation of diverse fungi.

Table.1 Different zones of Loyola College campus, Chennai, India

\begin{tabular}{|c|l|}
\hline S.No. & Zone \\
\hline 1 & Zoology department \\
\hline 2 & Physics department \\
\hline 3 & Main entrance \\
\hline 4 & J.D block \\
\hline 5 & History department \\
\hline 6 & LICET \\
\hline 7 & Chemistry department \\
\hline 8 & Foot ball ground \\
\hline 9 & B. Ed college \\
\hline 10 & Life building \\
\hline 11 & Church \\
\hline 12 & Boy's hostel \\
\hline 13 & Berchman's illam \\
\hline 14 & Commerce department \\
\hline 15 & Computer Academy \\
\hline 16 & Social media \\
\hline 17 & Social works department \\
\hline 18 & LICET \\
\hline 19 & Canteen \\
\hline 20 & Father's residence \\
\hline & \\
\hline
\end{tabular}


Table. 2 The colony morphology of different species isolated from different locations in Loyola college campus

\begin{tabular}{|c|c|c|c|c|c|c|c|}
\hline No & Locations & Code & Size & Colour & Nature of hyphae & Conidia shape & Name of the species \\
\hline \multirow[t]{2}{*}{1} & \multirow{2}{*}{ ZOOLOGY } & LZ1 & Small & Brown & Circular & Globose & Giagaspora margarita \\
\hline & & LZ3 & Medium & White cottony & Circular and regular & Sickle shape & Coleotrichum graminicola \\
\hline 2 & COMMERCE & LCOM1 & Medium & Black & Non-septate & Rough, irregular & Aspergillucs niger \\
\hline 3 & CHEMEMISTRY & LC1 & Medium & Black & Non-septate & Rough and irregular & Aspergillus niger \\
\hline \multirow{3}{*}{4} & \multirow{3}{*}{ PHYSICS } & LPHY1 & Large & Bluegreen & Non-septate & Irregular & Aspergillus clavatus \\
\hline & & LPHY2 & Medium & Blue green & Non-septate & Oval & Penicillium chrysogenum \\
\hline & & LPHY3 & Medium & Black & Non-septate & Oval conidia & Rhizopus stolonifer \\
\hline \multirow{3}{*}{5} & \multirow{3}{*}{ HISTORY } & LH1 & Medium & White & Broad non septate & Ellipsoidal & Mucor sp. \\
\hline & & LH2 & Medium & Brown & Non-septate & Globose & Rhizopus orzae \\
\hline & & LH3 & Medium & Black & Non-septate & Rough and irregular & Aspergillus niger \\
\hline \multirow[t]{2}{*}{6} & \multirow{2}{*}{ LICET } & LT1 & Small & Brownish black & Septate & Oval conidia & Cladophialophora sp. \\
\hline & & LT2 & Small & Grey & Septate, hyaline & Ellipsoidal & Arthridium phaeospermum \\
\hline \multirow[t]{2}{*}{7} & \multirow{2}{*}{ SOCIAL WORKS } & LS1 & Medium & White & Non septate & Ellipsoidal & Mucor sp. \\
\hline & & LS2 & Large & Green & Non septate & Globose & Aspergillus clavatus \\
\hline \multirow{2}{*}{8} & \multirow{2}{*}{ SOCIAL MEDIA } & LSM1 & Medium & Black & Non-septate & Rough and irregular & Aspergillus niger \\
\hline & & LSM & Medium & Brown & Non-septate & Oval & Aspergillus variabilis \\
\hline \multirow[t]{2}{*}{9} & \multirow{2}{*}{ CANTEEN } & LS1 & Medium & White & Broad non septate & Ellipsoidal & Mucor sp. \\
\hline & & LS3 & Medium & Green & Non-septate & Irregular & Aspergillus clavatus \\
\hline \multirow{3}{*}{10} & \multirow{3}{*}{ B.ED } & LBE1 & Medium & White & Non-septate & Ellipsoidal & Mucor sp. \\
\hline & & LBE2 & Small & Turf grey & Non-septate & Ovate & Cunningamella bertholletiae \\
\hline & & LBE3 & Large & Black & Non-septate & Rough and irregular & Aspergillus niger \\
\hline 11 & CHURCH & LC1 & Medium & Black & Non-septate & Rough and irregular & Aspergillus niger \\
\hline 12 & JD BLOCK & LJD1 & Large & Black & Non-septate & Rough and irregular & Aspergillus niger \\
\hline \multirow{2}{*}{13} & \multirow{2}{*}{ BERCHMANS } & LB1 & Large & Black & Non-septate & Rough and irregular & Aspergillus niger \\
\hline & & LB2 & Medium & Black & Non-septate & Irregular & Aspergillus sydowii \\
\hline \multirow[t]{2}{*}{14} & \multirow{2}{*}{ BOYS HOSTEL } & LBH1 & Medium & White & Non-septate & Ellipsoidal & Mucor sp. \\
\hline & & LBH1 & Large & Black & Non-septate & Rough and irregular & Aspergillus niger \\
\hline 15 & FATHERS HOUSE & LFH1 & Medium & Black & Non-septate & Rough and irregular & Aspergillus niger \\
\hline
\end{tabular}


The soil samples were collected from the month of September 2015 to March 2016 in Loyola college campus at various locations. In the present study, the isolated fungi were identified on the basis on of cultural, microscopic and morphological characteristics. It is known that PDA is the general medium most widely used in the isolation of fungi, having a complete nutritional basis (Agrios, 1988); this is probably the reason why colony development was faster with respect to other media. Earlier work reported that maximum growth of fungi, potatodextrose was most favourable (Maheshwari, 2000). In my experiment I also used Potato Dextrose Agar medium, the growth of the fungus was maximum. Fungal population dominate the soil food web (although they are less in number than the bacteria). Fungi have 40-55\% carbon use efficiency so they store and recycle more carbon $(\mathrm{C})$ compared to bacteria.

\section{Acknowledgements}

We, the authors sincere thanks to UGC for financial help and the Dr. Swaranjit Singh Cameotra, Professor, Deputy Director, Isititute of Microbial Technology, Chandigarh for idenfication and also we thankful to our Loyola College management and lab assistants for helping to do this research work.

\section{References}

Abd-Elhalem, M. El-Sawy, B.T., Gamal, R.F. and Abou-Taleb, K.A. 2015. Production of amylases from Bacillus Amyloliquefaciens under submerged fermentation using some agroindustrial by-products. Ann. Agric. Sci., 3(4): 110-115.

Akcan, N., Uyar, F. and Guven, A. 2011. Alpha-Amylase Production by Bacillus.

Adams, C.P., Bamford, K. M. and Early, M. P. 1990. Principles of Horticulture (3rd
Ed.), utterworth Heineman, p. 25.

Agrios, G. 1988. Plant Pathol., (3rd ed). In: Noriega Group, editor Mexico: Academic Press, p. 803.

Bacon, C.W., 1990. Isolation, culture and maintenance of endophytic fungi of grasses In: Isolation of biotechnological organisms from nature. ed.by $P$. Labeda, McGraw- Hill, New York, USA.

Bills, G.F. and Polishook, J.D. 1994. Abundance and diversity of microfungi in leaf litter of a lowland rain forest in Costa Rica. Mycologia, 86: 187-198.

Dick, R. 2009. Lecture on Soil Fungus in Soil Microbiology, Personal Collection of R. Dick, The Ohio State University School of Environment and Natural Resources, Columbus, $\mathrm{OH}$.

Isaac, S.J.C. Frankland, R. Watling, and A.J.S. Whalley. 1993. Aspects of Tropical Mycology, Cambridge University Press, Cambridge, U.K.

Karthikeyan, P., Kanimozhi, K., Senthilkumar, G., Panneerselvam, A. and Ashok, G. 2014. Optimization of Enzyme Production in Trichodermaviride using Carbon and Nitrogen source. Int. J. Curr. Microbiol. App. Sci., 3(1): 88-95.

Kirk, J.L., Beaudette, L.A., Hart, M., Moutoglis, P., Klironomos, J.M., Lee, H. and Trevor, J.T. 2004. Methods of studying soil microbial diversity. $J$. Microbiol. Methods, 58:169-188.

Labeda, D.P. 1996. DNA relatedness among verticil-forming Streptomycesspecies (formerly Streptoverticillium species). Int. J. Syst. Bacteriol., 46: 699-703.

Lowenfels, J. and Lewis, W, 2006. Teaming with Microbes: A Gardener's Guide to the Soil Food Web, Chapter 3: Bacteria Timber Press: Portland, Oregon.

Magdoff, F. and Van Es, H. 2009. Building Soils for Better Soil: Sustainable Soil Management, Chapter4: The Living 
Soil (3rd ed.). Sustainable Agriculture Network, Handbook Series Book 10. SARE Sustainable Agriculture Research \& Education: Beltsville, Maryland.

Maheshwari, R., Bhardwaj, G. and Bhat, M.K. 2000. Thermophilic fungi: Their physiology and enzymes, Microbiology Mol. Biol. Rev., 63: 461-488.

Mycology Guidebook Committee, Mycological Society of America, Stevens, R.B., ed. 1981. Mycology Guidebook. University of Washington Press, Seattle.

Ratna Kumar, P.K., Hemanth, G.P. Shiny Niharika and Samuel, K. Kolli. 2015. Isolation and identification of soil mycoflora in agricultural fields at Tekkali Mandal Srikakulam District. Int. J. Adv. Pharmacol., 14(2): 484-490.

Seifert, K.A. 1992. Isolation of filamentous fungi, In: D.P. Labeda (ed.) Isolation of Biotechnological Organisms from Nature. Mc-Graw-Hill, New York. pp. 21-51.

Stefanis, C., Alexopoulos, A., Voidarou, C., Vavias, S. and Bezirtzoglou, E. 2013. Principal methods for isolation and identification of soil microbial communities. Folia Microbiol., (Praha). 58(1):61-8. doi: 10.1007/s12223-012-0179-5.

Sylvia, D.M., Hartel, P.G. Fuhrmann, J.J. and Zuberer, D.A. 2005. Principles and Applications of Soil Microbiol., $\left(2^{\text {nd }}\right.$ ed.). Edited by David M. Sylva, Pearson Prentice Hall, Upper Saddle River: New Jersey.

Waksman, S.A. 1927. Principles of Soil Microbiol., Williams and Wilkins Co. Baltimore, Md. pp. 1-654.

\section{How to cite this article:}

Raja, M., G. Praveena and John William, S.. 2017. Isolation and Identification of Fungi from Soil in Loyola College Campus, Chennai, India. Int.J.Curr.Microbiol.App.Sci. 6(2): 1789-1795. doi: http://dx.doi.org/10.20546/ijcmas.2017.602.200 